\title{
PENERAPAN E-COMMERCE UNTUK MENINGKATKAN PENJUALAN PADA TOKO PIKO-PIKO BABY \& KIDS SHOP
}

\author{
Wengku Hutomo $^{1)}$, Bima Cahya Putra ${ }^{2)}$ \\ ${ }^{1}$ Sistem Informasi, Fakultas Teknologi Informasi, Universitas Budi Luhur \\ ${ }^{1,2} \mathrm{Jl}$. Raya Ciledug, Petukangan Utara, Kebayoran Lama, Jakarta Selatan 12260 \\ E-mail: tomo.wengku@gmail.com ${ }^{1)}$, bimo.cahyoputro@budiluhur.ac.id ${ }^{2)}$
}

\begin{abstract}
Abstrak
Jual beli produk dengan pelanggan merupakan proses yang sering dialami oleh para pedagang/usaha yang bergerak pada bidang penjualan. Proses intraksi penjualan biasa sering dilakukan secara terbuka atau langsung dan bertatapan dengan pelanggan. Misalnya yang terjadi pada Toko Piko-Piko Baby \& Kids Shop, toko ini masih menggunakan konsep toko fisik seperti pada umumnya sehingga penjualan hanya dapat diakses dengan datang ke toko saja, media promosi hanya menggunakan kertas sehingga jangkauan pemasaran tidak luas, untuk proses pemesanan pelanggan membutuhkan waktu dan tenaga dikarenakan harus datang ke toko untuk melakukan transaksi sehingga menyulitkan pelanggan sekaligus harus menyiapkan dana untuk transportasi datang ke toko. Oleh karna itu penelitian ini membahas penerapan berbasis e-commerce untuk meningkatkan penjualan pada toko piko-piko baby \& kids shop dengan menggunakan konsep e-commerce dapat mengembangkan penjualan dengan jangkauan pasar lebih luas, kemudahan akses informasi media promosi kepada pelanggan dan memberikan pelayanan bertransaksi mudah dan efektif.
\end{abstract}

Kata kunci: Business Model Canvas, E-Commerce, Perlengkapan Bayi.

\section{PENDAHULUAN}

\subsection{Latar Belakang}

Pemanfaatan teknologi informasi dalam persaingan bisnis semakin modern dari waktu ke waktu sudah terasa dampaknya dimana sebagian besar perusahaan atau instansi tidak dapat lepas dari komputerisasi dan internet. Pada hal ini, komputer dan internet merupakan fasilitas yang saling berkaitan dimana komputer merupakan alat untuk mengelola data dan internet merupakan sumber data. Dengan internet sebagai sumber data/informasi dapat memudahkan pengguna untuk mengakses informasi ataupun sebagai peluang bisnis salah satunya yang sedang hangat/populer adalah bisnis online atau biasa disebut dengan $e$-commerce.

Penjualan adalah merupakan bagian dari fungsi perusahaan yang didalamnya terdapat fungsi produksi dan administrasi[1]. Toko piko-piko baby \& kids shop adalah suatu jenis usaha dibidang penjualan perlengkapan bayi dan anak. Pada toko ini menjual berbagai perlengkapan bayi dan anak seperti pakaian, maianan anak, sepatu anak dan peralatan anak lainnya seperti selimut dan tempat makan. Untuk penjualan masih menggunakan toko fisik sebagai proses jual beli sehingga membutuhkan biaya yang tidak sedikit. Pada era digital ini cara tersebut terbilang kurang efektif untuk mendapatkan jangkauan pasar yang luas.

Kendala lain dengan berjalannya bisnis toko piko-piko baby \& kids shop adalah pencatatan transaksi tidak beraturan dan sering sekali terjadi kehilangan data pencatatan, pencatatan transaksi penjulan masih menggunakan media kertas sehingga dapat mudah hilang dan rusak, tidak dapat menyebarkan potongan harga yang dimiliki karena tidak memiliki data pelanggan, media promosi yang digunakan menggunakan brosur atau kertas cetak sehingga jangkauan pasar hanya sebatas disekitar toko, dan untuk proses pemesanan terbilang cukup memakan waktu dimana pelanggan harus datang ke toko terlebih dahulu untuk melakukan transaksi pembelian produk serta terbatas dengan waktu operasional toko.

Electronic commerce adalah pembelian, penjualan, pemesanan produk dan jasa melibatkan sistem elektronik melalui internet[2]. Dengan hadirnya e-commerce dapat membuat perubahan besar pada toko piko-piko baby \& kids shop terutama pada transaksi. Transaksi akan menjadi modern dan lebih cepat. Adanya penerapan $e$ commerce ini juga dapat mempermudah semua sekmen diantara lain seperti pelanggan, staff admin dan terutama pemilik.

\subsection{Tujuan dan Manfaat Penulisan}

a. Tujuan Penulisan

Penulis membuat sistem e-commerce pada toko piko-piko baby \& kids shop ini bertujuan dapat atau mampu menyelesaikan masalah dan mengurangi masalah yang sedang berjalan proses bisnis saat ini. Dalam penyampaian informasi secara efisien, efektif dan valid ini sesuai dengan kebutuhan pada proses bisnis berjalan sehingga penulisan ini dapat mempermudah pekerjaan/membuat efisien. Adapun maksud dan tujuan penulisan ini adalah: 
1. Dengan diterapkannya sistem e-commerce, admin atau pemilik dapat memberikan informasi potongan harga kepada customer melalui via whatsapp atau email.

2. Sebagai sarana memudahkan customer dalam bertransaksi tanpa terbatas dengan jam kerja toko.

b. Manfaat Penulisan

Manfaat dari penulisan tugas akhir ini diharapakan dapat menjadi solusi atas permasalahan atau kendala dari toko piko-piko baby \& kids shop sebagai berikut:

1. Memberikan sarana atau fasilitas kepada admin untuk mempromosikan produk yang memiliki potongan harga.

2. Memudahkan customer dalam melakukan pemesanan tanpa batasan waktu.

\subsection{Ruang Lingkup}

Dalam penulisan ini, penulis mambuat ruang lingkup agar tidak menyimpang dalam pokok permasalahan yaitu:

a. Sistem electronic commerce dibangun menggunakan konsep B2C (Business to Customer).

b. Menggunakan CMS wordpress untuk pembuatan e-commerce.

c. Memiliki beberapa tahap dalam melakukan transaksi proses pemesanan, pembayaran dan proses kirim produk.

d. Memiliki fitur keranjang belanja, delivery order dan layanan chat yang direct ke whatsapp pada website.

\section{METODE PENELITIAN}

Metode penelitian merupakan suatu unsur yang penting dalam penulisan penelitian. Berikut merupakan metode penelitian yang penulis buat antara lain:

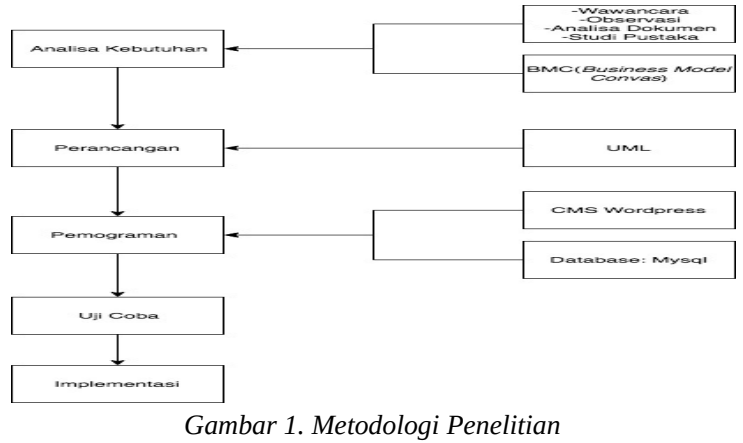

Berikut ini merupakan penjelasan pada gambar 1 kerangka pemikiran yang penulis buat antara lain: a. Analisa Kebutuhan
Pada penulisan penelitian ini penulis menggunakan teknik wawancara, observasi, analisa dokumen dan studi pustaka untuk mengumpulkan data-data yang dibutuhkan dalam pembuatan penulisan ini dan membuat BMC (Business Model Canvas) sebagai salah satu detail dokumen yang sedang berjalan.

b. Perancangan

Pada tahapan ini peneliti melakukan analisa dan perancangan sistem menggunakam UML (Unified Modeling Language) untuk membuat proses bisnis usulan dan diagram yang dibutuhkan seperti Activity Diagram, Use Case Diagram, Class Diagram, dan Sequence Diagram.

c. Pemograman

Pada tahap pembuatan program ini, peneliti menggunakan CMS (Content Management system) yaitu wordpress untuk membangun program dan menggunakan database mysql. Program yang dibuat sesuai dengan perancangan yang sudah ditetapkan.

d. Pengujian

Sebelum dilakukan implemetasi kepada toko piko-piko baby \& kids shop. Penulis melakukan uji coba pada fungsional website yang telah dibuat sesuai dengan perancangan yang telah dibuat.

e. Implementasi

Setelah melakukan pengujian terhadap sistem dan berjalan dengan baik. Tahap selanjutnya menerapkan sistem yang sudah di uji tersebut kepada toko piko-piko baby \& kids shop.

\section{HASIL DAN PEMBAHASAN}

\subsection{Business Model Canvas}

BMC (Business Model Canvas) adalah kerangka kerja atau struktur kerja untuk memetakan suatu bisnis agar cara kerja dari bisnis tersebut lebih optimal dan terstruktur[3]. Berikut merupakan Business Model Canvas yang telah penulis buat sebagai berikut:

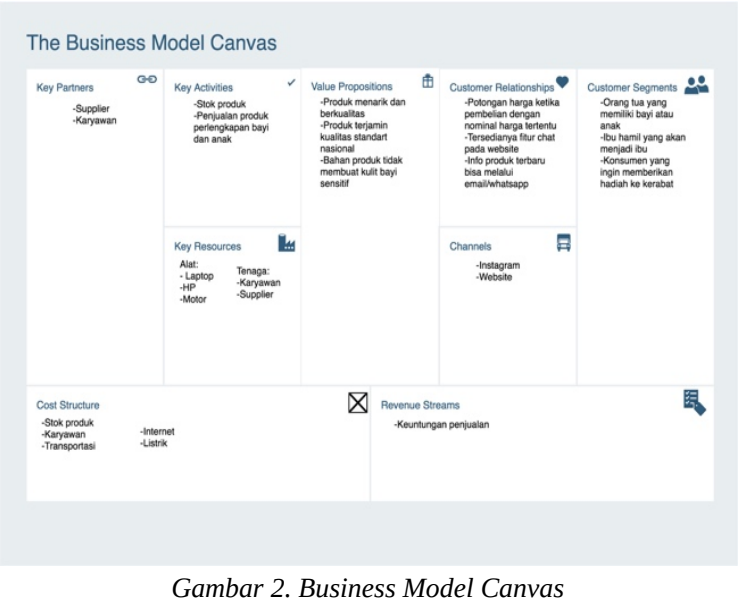


Berikut adalah penjelasan tentang Business Model Canvas pada gambar 2 yaitu sebagai berikut:

a. Key Partners

Merupakan pihak yang menjadi pembantu untuk mengoptimalkan alokasi sumber daya pada bisnis toko Piko-Piko Baby \& Kids Shop, dengan menjalin hubungan dengan pihak yang terkait seperti supplier.

\section{b. Key Activities}

Berisi aktivitas pokok atau yang paling utama dalam menjalankan bisnis.

c. Value Proposition

Adalah nilai atau kualitas produk yang ditawarkan kepada pelanggan agar pelanggan minat untuk membeli produk.

d. Customer Relationship

Tentang cara mempromosikan, menjalin hubungan dan menjaga hubungan agar pelanggan tidak mudah berpaling ke toko yang lain.

e. Customer Segment

Berisi untuk menentukan lingkup atau sasaran pasar yang dituju dan menggolongkan bedasarkan kebutuhan pelanggan.

f. Key Resources

Berisi tentang apa saja yang dibutuhkan toko untuk menjalankan bisnis yang sedang berjalan. Resource ini pun dapat berupa sebuah pinjaman atau sebuah usaha.

\section{g. Channels}

Merupakan strategi atau cara untuk memasarkan produk agar pelanggan dapat membeli dan mendapatkan informasi produk secara detail.

h. Cost Structure

Pengeluaran atau biaya yang dikeluarkan bisnis agar usaha tersebut dapat membentuk, memproduksi dan memberikan layanan atau memasarkan produk.

i. Revenue Streams

Merupakan hasil pendapatan yang dihasilkan oleh penjulan dan penghasilan tambahan.

\subsection{Activity Diagram Sistem}

Activity diagram merupakan salah satu diagram yang menggambarkan sebuah alur atau proses aktivitas pada bisnis proses tersebut[4].

a. Proses Register

Pada Gambar 3, pada tahap ini untuk melakukan pemesanan atau transaksi pada website toko Piko-Piko Baby \& Kids Shop user diwajibkan untuk melakukan register terlebih dahulu. Pada proses regiter user pilih menu daftar/ masuk kemudian masukan identitas asli seteleah selesai pilih register. Jika terjadi kesalahan atau tidak sesuai user melakukan input data kembali.

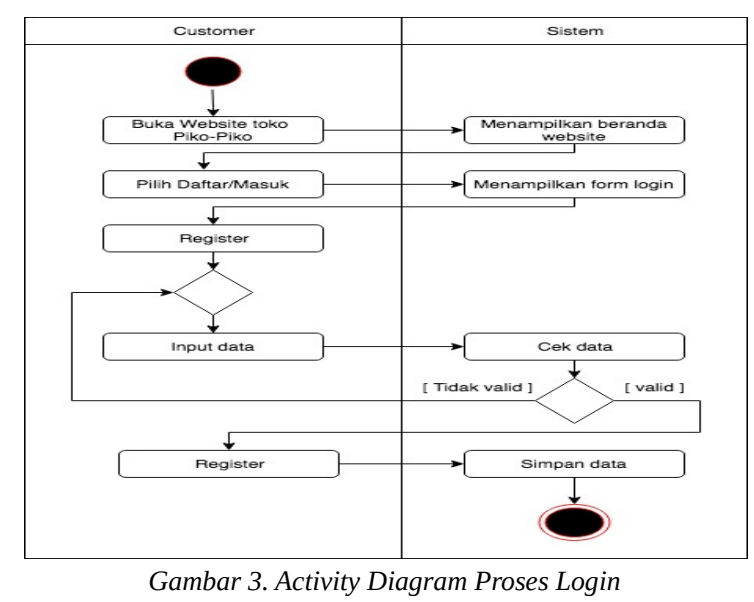

b. Proses Pemesanan Barang

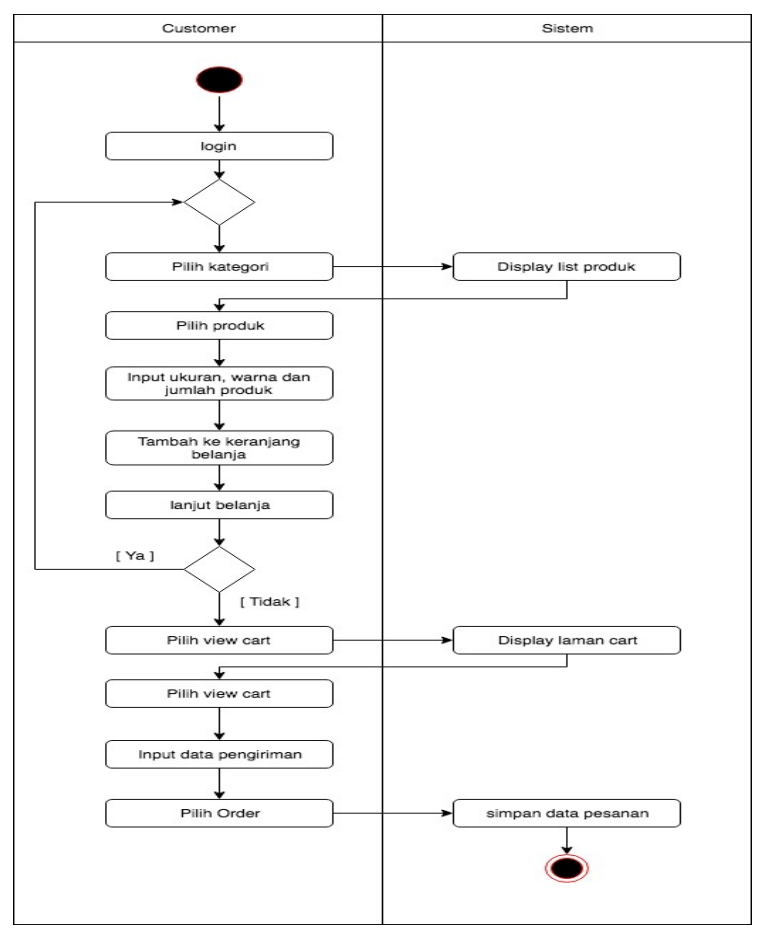

Gambar 4. Activity Diagram Proses Pemesanan Barang

Pada gambar 4, proses pemesanan produk pelanggan wajib melakukan login terlebih dahulu. Setalah login, pelanggan pilih menu kategori untuk memilih kategori apa yang sedang dicari dan melihat produk yang tersedia. Ketika sudah dapat produk yang ingin dibeli kemudian pilih produk dan pilih ukuran, warna dan jumlah produk. Setelah selesai lakukan checkout dan masukan data pengiriman. Setelah selesai pilih order.

c. Proses Konfirmasi Pembayaran

Pada gambar 5, tahap ini pelanggan melakukan pembayaran melalui transfer bank atau ATM. Pembayaran hanya dapat melakukan transfer dikaranakan belum bekerja sama dengan pihak 
ketiga. Setelah selesai transfer, mengentry bukti pembayaran lalu pilih kirim. Ketika pembayaran telah sesuai dengan pemesanan bagian staff melakukan approval untuk cek dan konfirmasi pembayaran. Kemudian setelah sesuai staff pun melakukan approve sehingga otomatis sistem akan update status pemesanan.

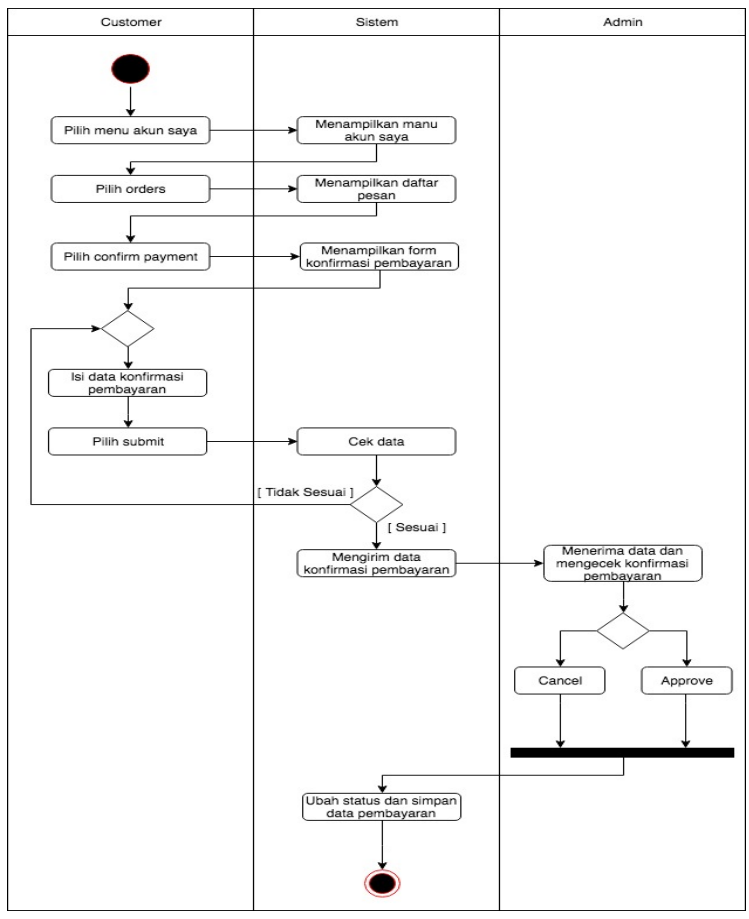

Gambar 5. Activity Diagram Proses Konfirmasi Pembayaran

\section{d. Proses Laporan}

Pada gambar 6, Staff akses website dengan lakukan login terlebih dahulu, lalu staff pilih menu laporan dan melakukan cetak laporan yang dibutuhkan serta berikan laporan kepada pemilik sebagai laporan bulanan atau per periode.

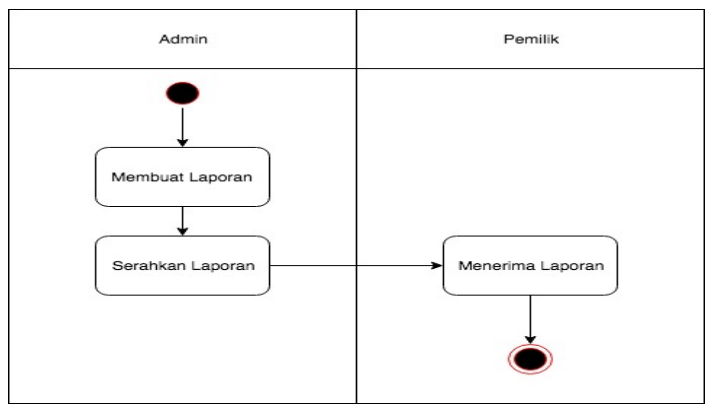

Gambar 6. Activity Diagram Laporan

\subsection{Use Case Diagram}

Use case diagram adalah diagram yang menggambarkan fungsi keterkaitan antara sistem dan aktor.
a. Use Case diagram master

Pada gambar 7 ini merupakan use case diagram master sebagai berikut:

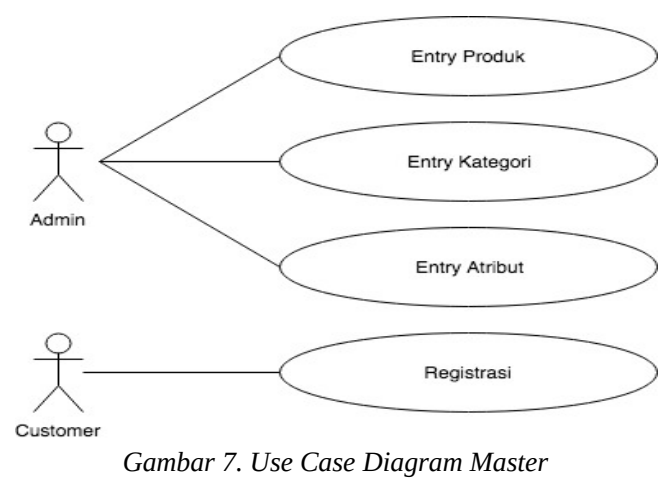

b. Use Case Transaksi

Pada gambar 8 dibawah ini merupakan use case diagram transaksi, antara lain sebagai berikut:
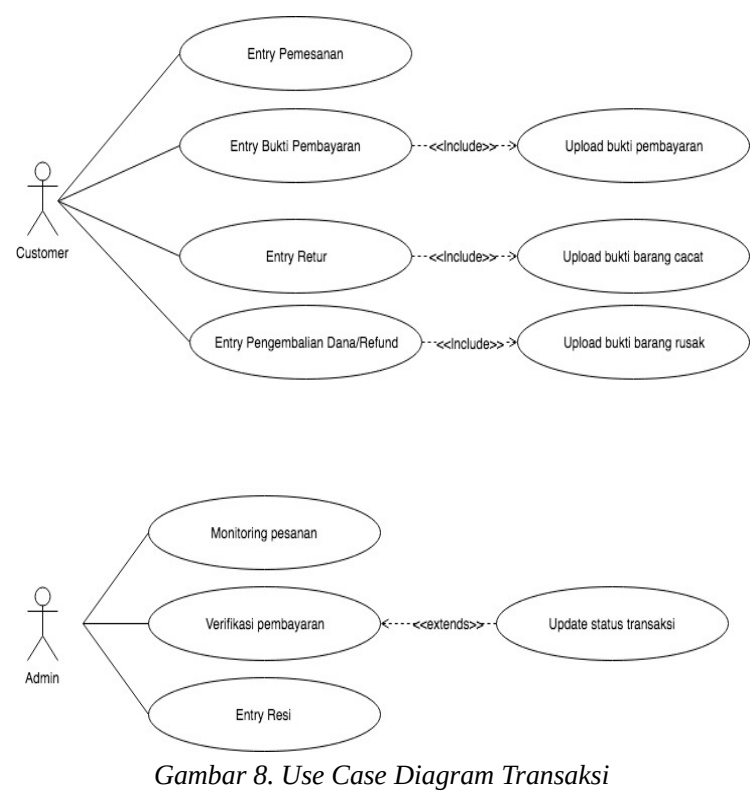

c. Use Case Laporan

Pada gambar 9 selanjutnya merupakan use case diagram laporan, sebagai berikut:

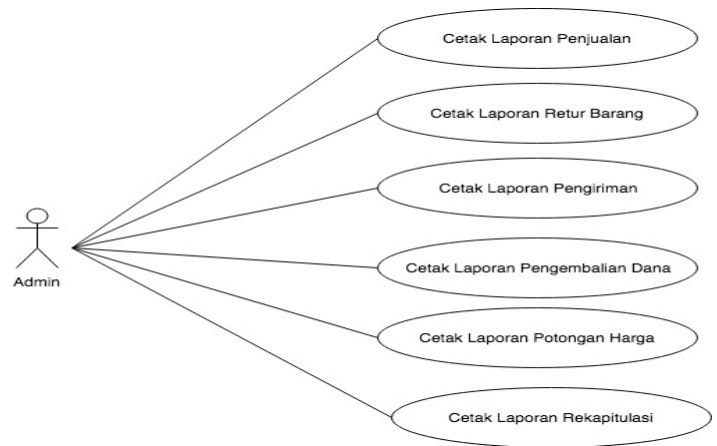

Gambar 9. Use Case Diagram Laporan 


\subsection{Class Diagram}

Class diagram adalah satu model yang menggambarkan struktur antar class pada tiap table atau setiap entitas. Pada gambar 10 berikut merupakan class diagram:

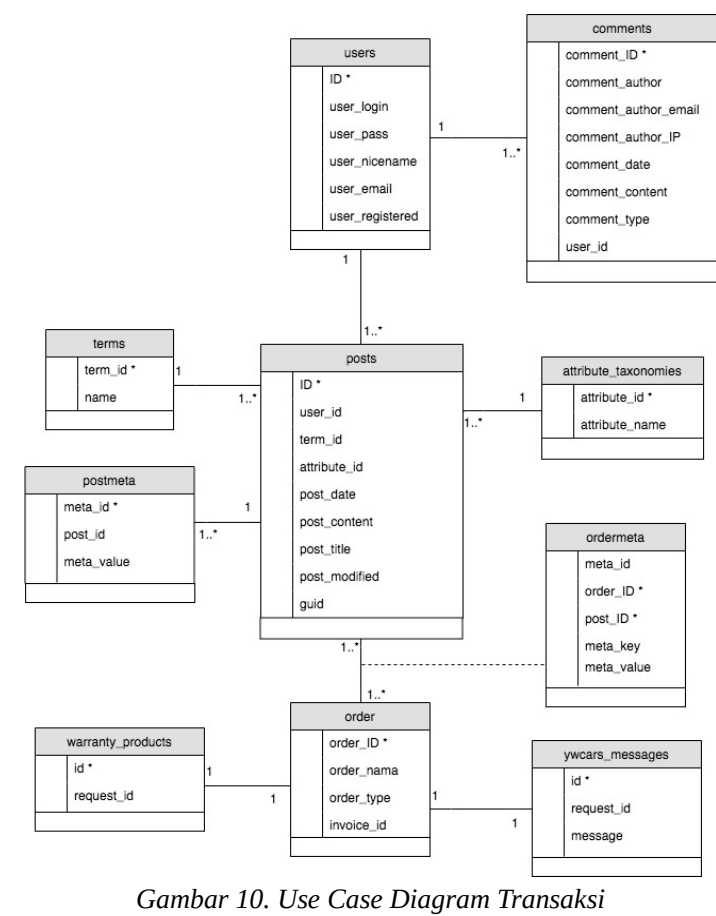

\subsection{Strukur Tampilan Menu}

a. Frontend

Pada gambar 11 struktur tampilan menu frontend yang digambarkan penulis sebagai berikut:

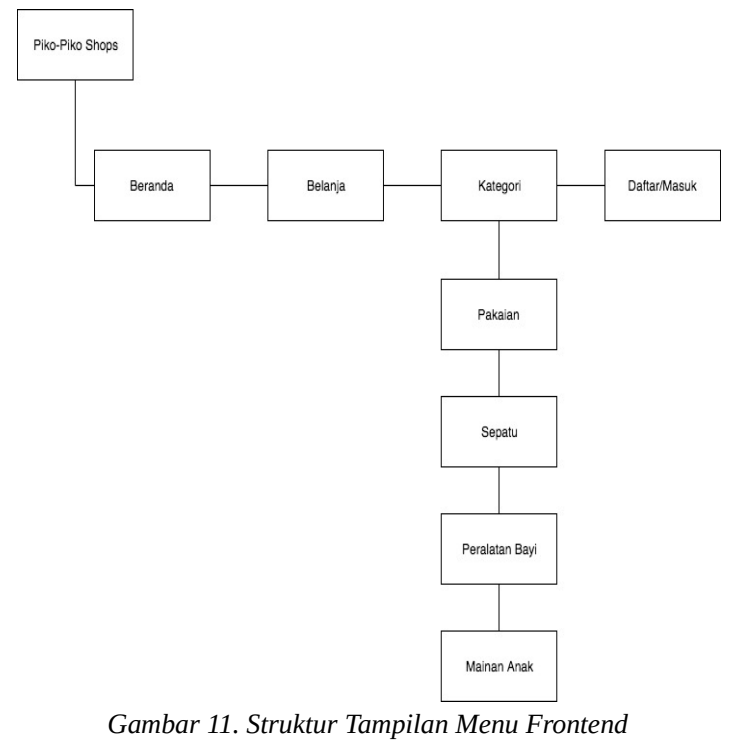

b. Backend

Pada gambar 12 tampilan menu struktur ini penulis menggambarkan menu yang digunakan oleh admin atau struktur tampilan pada admin. Sebagai berikut:

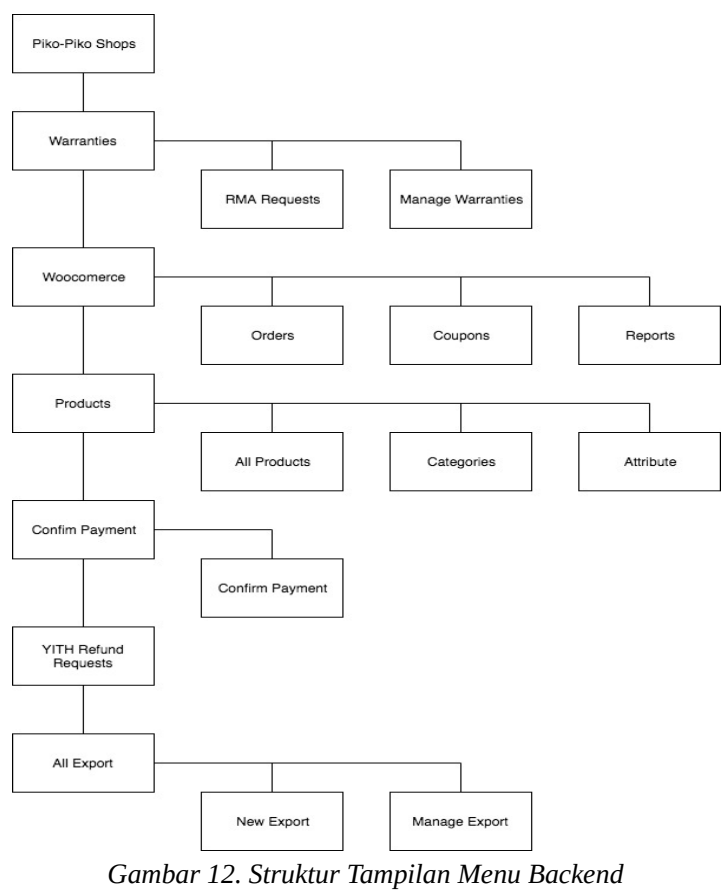

3.6. Rancangan Layar

a. Rancangan Layar Belanja

Gambar 13 berikut merupakan menu belanja yang berisi tentang daftar list produk yang tersedia. Sebagai berikut:

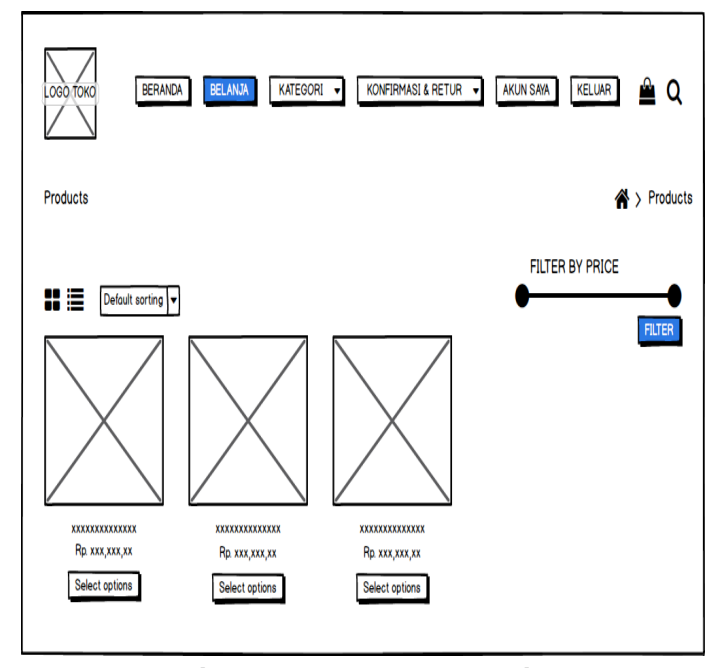

Gambar 13. Rancangan Layar Belanja

b. Rancangan Layar Konfirmasi Pembayaran

Pada gambar 14 berikut adalah laman form menu konfirmasi pembayaran. Pelanggan memasukan data bukti transaksi setelah melakukan pembayaran: 


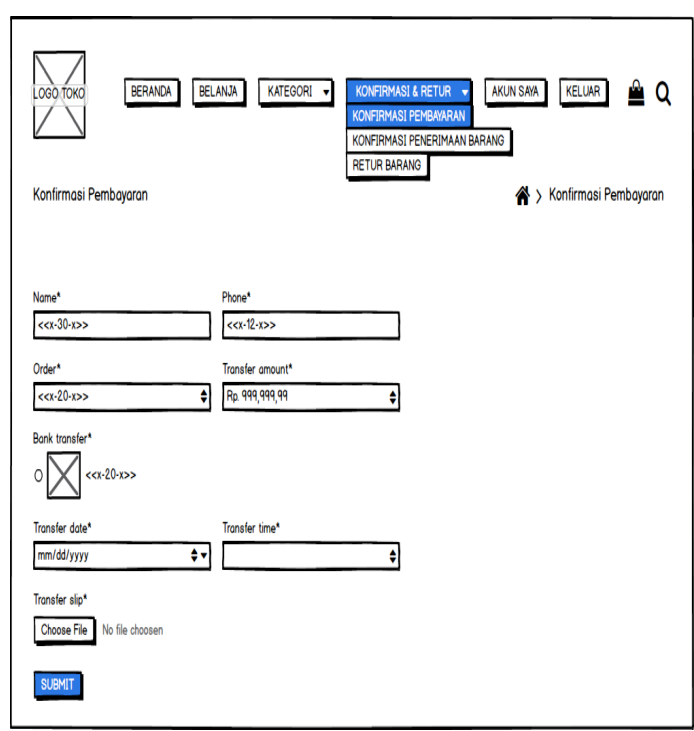

Gambar 14. Rancangan Layar Konfirmasi Pembayaran

c. Rancangan Layar Laporan Rekapitulasi

Gambar 15 rancangan layar ini adalah laporan rekapitulasi bedasarkan kategori penjualan, dimana laporan tersebut dapat menampilkan data penjualan kategori bedasarkan periode atau dalam hitungan bulan:

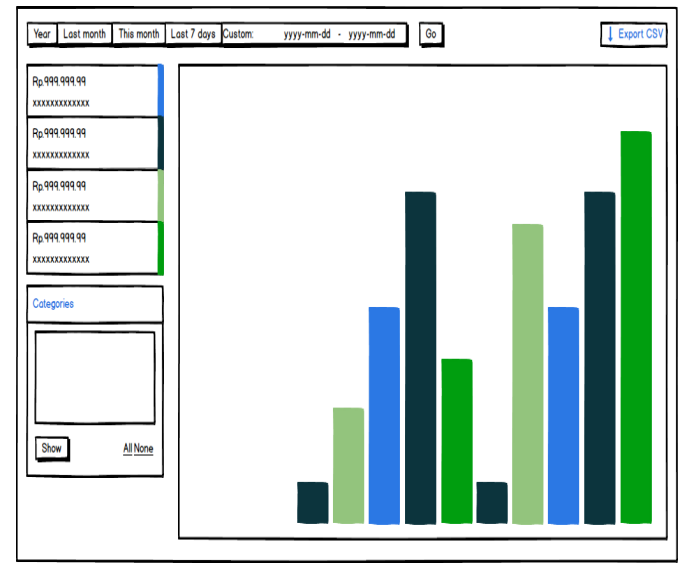

Gambar 15. Rancangan Layar Laporan Rekapitulasi

\subsection{System Sequence Diagram}

System sequence diagram merupakan diagram pengambaran interaksi pada setiap objek didalam sistem[5]. Dibawah ini penulis membuat system sequence diagram, sebagai berikut:

a. Login

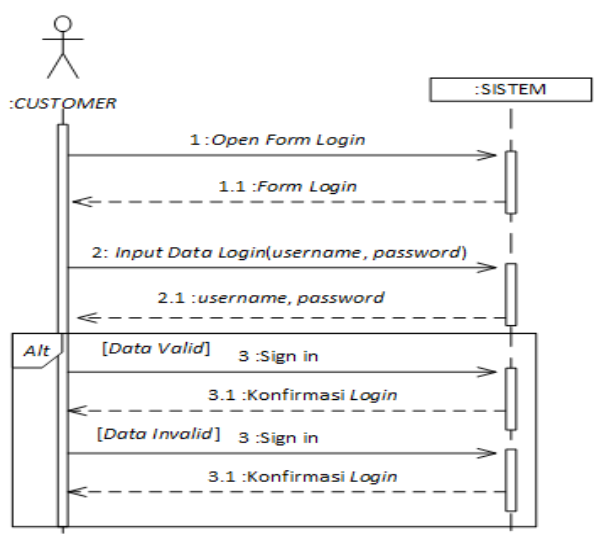

Gambar 16. Entry Login

b. Entry Konfirmasi Pembayaran

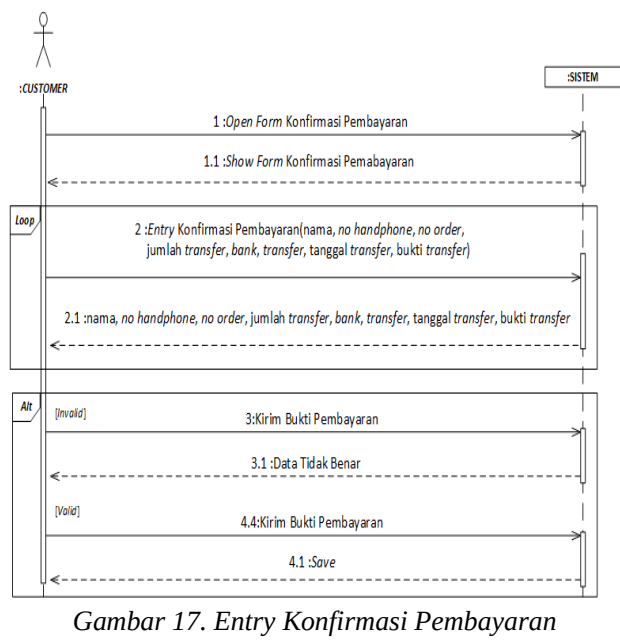

c. Laporan Produk Terlaris

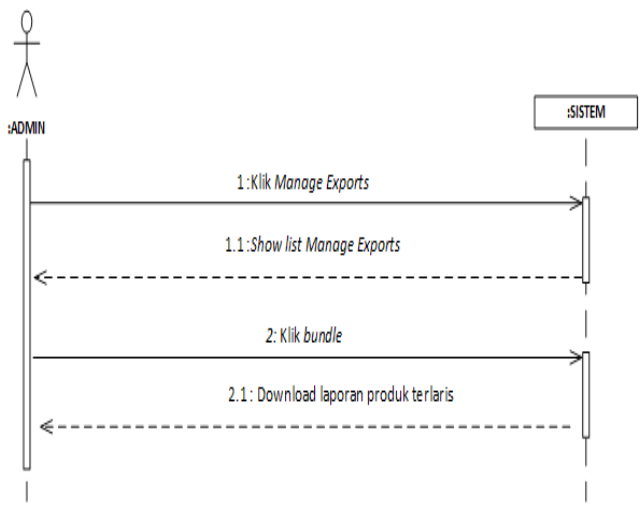

Gambar 18. Laporan Produk Terlaris

\section{KESIMPULAN}

Hasil dari penelitian ini, penulis dapat memberikan kesimpulan, diantaranya: 
a. Sebagai salah satu media transaksi pemesanan terbaru dengan harapan meningkatkan hasil penjualan.

b. Tersedianya fitur promosi pada halaman website dan dapat memberikan notifikasi kepada pelanggan melalui email serta terdapat media promosi melalui social media sehingga media promosi semakin luas dan mudah diakses oleh pelanggan.

c. Dengan dibuatnya website resmi, pelanggan dapat melakukan proses transaksi lebih cepat tanpa mengkhawatirkan jangkauan.

\section{DAFTAR PUSTAKA}

[1] Enterprise, J. . Langkah Pertama Jadi Pengusaha UMKM. Yogyakarta: Jubilee Enterprise, 2016, p.96.

[2] Komputer, W. Membuat Toko Online dengan Wordpress dan WP E-Commerce. Jakarta: PT Elex Media Komputindo, 2015, p.8.

[3] Royan, Frans M. Bisnis Model Kanvas Distributor. Jakarta: Gramedia Pustaka Utama, 2014, p.1.

[4] Mulyani, Sri. Metode Analisis dan Perancangan Sistem. Bandung: Abdi Sistematika, 2017, p.38.

[5] [5] Rusmawan, U. Teknik Penulisan Tugas Akhir dan Skripsi Pemograman. Jakarta: PT Elex Media Komputindo, 2017, p.84. 